\title{
Over My Dead Body There Is an Ideal Utopia: Comments on Kellehear's Paper
}

\author{
Carl B. Becker, Ph.D. \\ Tsukuba University
}

\begin{abstract}
Allan Kellehear's near-death experiencers (NDErs) report perceiving a utopia beyond death. I examine the logical implications and philosophical possibilities of such a realm, and come to three conclusions. First, the realms described by NDErs, if taken at face value, are far from utopian, rather resembling travelers' romances with exotic lands. Second, any truly utopian postmortem society is so far removed from our present world as to be morally irrelevant to our own. And third, only an ideational postmortem utopia, of the sort exemplified by Pure Land Buddhist theology, can avoid both the non-utopian nature of NDErs' descriptions and the irrelevance of postmortem utopias.
\end{abstract}

Allan Kellehear is becoming recognized as a highly creative and enterprising young sociologist who tackles topics beyond the province of old-guard sociology. His articles on near-death experiences (NDEs) in China (Kellehear, Heaven, and Gao, 1990) and in shipwrecked sailors (Kellehear, 1990) are important advances in the understanding of cultural visions. I was pleased to see his latest contribution, "NearDeath Experiences and the Pursuit of the Ideal Society," but that article raised as many problems as it answered. Some of these were problems of Kellehear's methodology, but others demanded further philosophical and sociological clarification.

Kellehear bracketed all discussion of the "reality" of NDEs. This was politically a wise move to avoid a debate irrelevant to his sociological

Carl B. Becker, Ph.D., is Assistant Professor of Philosophy at Tsukuba University. Reprint requests should be addressed to Dr. Becker at the Institute of Philosophy, Tsukuba University, Tsukuba City 305, Japan. 
focus. He treated NDEs as images only potentially valuable for what they tell us about human dreams and disaffections with present societies. Yet sometimes he wrote as if these visions had an external reality of their own, not arising from within the mind of the perceiver, but appearing to the perceiver from without. At times, he even implied that these NDE utopias might be real realms of postmortem human activity in their own right. If his methodological strategy was to set aside all concern with the reality of these visions in order to focus solely on their social and psychological implications, then he should have consistently followed that approach.

Kellehear's NDErs reported perceiving an apparent utopia. I accept Kellehear's bracketing the real existence of such a utopia; whether it really exists is not at issue here. Instead, I will examine their assertion from a philosophical perspective. Three issues arise. First, could a utopia of the sort these NDErs saw even be intelligibly conceived? I argue that NDErs' assertions contradict the idea of a utopia.

Second, would a utopia of the sort these NDErs saw have any moral implications for earthbound humans in pursuit of the ideal society? I argue that any truly utopian postmortem society is so far removed from our present world as to be morally useless. Third, what interpretation of NDErs' descriptions could conceive a utopia neither internally contradictory nor irrelevant to our moral development in pursuit of the ideal society? I argue that the Buddhist Pure Land utopia both avoids internal contradictions and provides hints toward human morality.

\section{Internal Problems in the Utopia of Kellehear's NDErs}

There are three elements of Kellehear's NDErs' descriptions that pose insurmountable problems in the construction of a coherent image of utopia. They are that this NDEr-derived utopia has physical objects and spatial limits, moral rules expected and enforced by the society, and no death. I argue that each of these factors conflicts with the assertion that this society is anything like a utopia.

\section{Physical Limitations and Moral Problems}

Many of the moral evils of our human condition arise precisely because people want things or positions that exist in limited quan- 
tities. Even in utopia, apparently not everyone can be rich and famous. If intellectual or spiritual or moral merit of any kind is recognized in utopia, then there will still be a hierarchy, as Kellehear implied, a pecking order in which some people are more equal than others, and there will still be incentives to have or be something "better" than the next guy.

If there are still bodies, then some are going to be stronger or more handsome than others. If there are still cars or buildings or banquets, some are going to be faster or larger or tastier than others. Utopians will want more and "better" things than they presently have, especially if someone else already has more or better. Thus we are shunted back into the realm of competition, which the cooperative spirit of utopia was supposed to have made unnecessary, if not immoral. Put conversely, if there are things and limits to things in a postmortem society, they will militate against the utopian character of that realm.

\section{Social Rules and Moral Problems}

Kellehear's informants called their utopia a moral realm. Kellehear repeatedly alluded to the virtues that prevail in the realm of the utopian NDE: order, cooperation, self-development, learning, service, humanism, spiritualism, and kindness. However, most problems of morality arise not because people disagree with such values, but because they don't know how to act when these values at times conflict with each other.

For example, self-development and learning are inescapably individual values that result in the improvement and exaltation of the self; whereas values of cooperation and service result in the improvement and exaltation of the group or the "other." In utopia as on earth, individuals must choose whether to put personal freedom and priorities before or after those of the group.

Likewise, the values of courage and honesty may conflict with kindness and harmony. Should I choose courageously and honestly to expose problems, if doing so will not solve them but only scar other people's feelings? Or should I follow the dictates of kindness and harmony, remaining silent at the expense of courage and honesty? Living in a utopian realm will not obviate such moral dilemmas. Conversely, since these moral dilemmas inevitably arise in any rulegoverned society, it is exceedingly difficult to imagine a moral utopia. 


\section{Deathlessness and Moral Improvement}

Kellehear's NDErs reported that there is no death in their utopia. Since they glimpsed it only for a few hours rather than a lifetime, it is odd that they could make such an assertion with confidence. The problems with overcrowding in any finite realm of the dead stretch the credibility of their assertions. The fact that they did not encounter any funerals or rites of onward passage in their brief visions does not demonstrate that death never occurs there.

On the other hand, if it were true that there is no death in their visionary realm, then there would be little incentive for any denizen of utopia to work toward morality or self-improvement. In an infinite amount of time, whether one reaches some state of mind or being sooner or later has no temporal meaning within an eternal context. As John Hick (1976) argued, in a world where there is no death, people attempting suicide by jumping might float to the ground, the knives of murderers might turn to putty, and reasons for hygiene and nourishment disappear. Such a state might be theoretically imaginable, but it would have devastating consequences not only for the consistency of natural laws, but for incentives for moral and spiritual growth.

This picture is further complicated by the question of when utopiabound souls become so altruistic, cooperative, kind, self-actualizing, and spiritually humanistic. It is not clear whether any sort of embodied utopia could avoid values conflict except by a rather heavy-handed values education program at the expense of human freedom. Unfortunately, most humans, for most of their lives, are either morally unconscious or else morally conscious but incapable of acting with consistent morality, despite their best intentions. How is it that this multitude of humans who spent most of their existences on earth in search of self-protection, self-gratification, and self-aggrandizement, would come to treat others as more important and more worthy of protecting, gratifying, and aggrandizing than themselves?

This moral transformation of the human character is unquestionably desirable, but it is hard to imagine that it could happen overnight, simply based on the passing from an earthly body to a utopian one. If people retain the same levels of morality that they had during life on earth, then societies of the dead would have all the moral corruption that plagues our present world, and certainly could not be conceived of as utopian.

Alternatively, if the visionary world did enforce cooperative morality, it would come closer to Mao Zedong's China than to a free and capitalistic society: re-education camps and indoctrination programs 
would be necessary to counteract lifetimes of acquisitiveness. It is possible that such things lurk behind the scenes of NDErs' visions; but consideration of the workings required for any such "utopia" would reveal it as closer to a thought-controlled nightmare than to a happy heaven-as numerous utopian novelists have pointed out.

In many ways, NDErs' visions of utopia resemble the initial romance that many tourists feel after their first day in a new city. Shown the culture and the buildings, the prosperity and the social services, the cooperation in construction and places of learning, a tourist comes away from a brief encounter with almost any society thinking it wonderful and attractive. A longer investigation into any real society reveals the labor, suffering, and sacrifice upon which it is inevitably built. If NDErs had weeks and months to explore their images of utopia, they might find either that their images included elements far from utopian, or that their utopias included factors incompatible with human freedom.

Thus, while NDErs report a realm of great morality and harmony, it is hard to imagine how such a utopian harmony could be achieved. I do not deny that they said they saw utopias of moral harmony. But what they thought they saw is incompatible with what we know about human beings. Given the conditions that a utopia would include other beings, physical and spatiotemporal limitations, and people who had been educated on this world, then the kind of heavenly harmony NDErs report would be inconceivable.

\section{NDErs' Utopia As Morally Irrelevant}

I agree with Kellehear about the value of visualizing utopian societies for the potential inspiration they provide to our daily lives. For the sake of argument, let us imagine a society in which people found no moral conflict within their own actions, they were moral with respect to others, the hierarchy gave rise to no jealousies, there were no limits on supply, and there were no death. If these problems of interpersonal and moral conflict, material limitation, spiritual self-development, and death itself were nonexistent, such a utopia would be utterly irrelevant to the ways we behave here on earth.

It is precisely because we age, sicken, and die that there is urgency to what we must do in our short span on earth. It is precisely because there is only a limited amount of oxygen, ozone, fossil fuel, rain forest, arable land, precious ores (and on and on) that humans are not only 
plunged into a struggle for survival, but also recognize the need for a more cooperative and self-sustainable lifestyle.

Neither cooperation nor competition is in and of itself good or evil. Initially, development of the vast unused resources of the Americas, Australia, and Africa seemed a virtue, and competition brought people energy, wealth, and inventive genius-inevitably at the expense of the less competitive. Now, when competition threatens human health and survival, the cooperative ethic has begun to appeal. But this cooperation can only be achieved, as in China and Japan, at the expense of suppressing the geniuses and giants who might emerge from a more laissez-faire competition. Thus, the attractiveness of an ethic of cooperation depends largely on the presupposition of limitation. It would be curious if cooperation should still be the rule in utopia, if death and limitation were absent.

It is possible that from a higher spiritual standpoint, selflessness is to be preferred over selfishness, and cooperation over competition. But the problems of human societies are ultimately not what it might mean to be good in a deathless, diseaseless, unlimited society, but rather what it means to be good in a society tortured by death, disease, and limitation at every turn.

To be sure, morality and satisfaction can be achieved within such limitations. But the kind of self-sacrifice and challenges prerequisite to satisfaction under such earthly conditions would not be required in an unlimited utopia. From this perspective, the utopian vision gives us perhaps something toward which to strive, but not a model upon which to base present activity. Philosophically, we can imagine either a world with moral conflict, limitation, and death, which contradicts NDErs' idyllic utopia; or else a utopia with no death, limitation, or moral conflicts, with consequently minimal relevance to our behavior here on earth. Taken at face value, NDErs' visions are either relevant but non-utopian or utopian but irrelevant.

\section{The Buddhist Solution}

Based on my own research into Pure Land Buddhist NDEs (Becker, 1981, 1984), I suggest that if NDErs' visions are interpreted along a Mahayana Buddhist model, the difficulties in the above visions of "social-materialist eternity" can be resolved. This is because the Buddhist model would replace physical/material things with mindgenerated images, moral and social rules with the search for meaning and enlightenment, and deathlessness with the passage to a disem- 
bodied selfless state, or nirvana. Furthermore, these philosophical differences have important implications for our lives here and now.

\section{Physical Things Versus Mental Images}

The Buddhist Pure Land is purely mind-generated; it is a projection of the ideas, desires, thoughts, and presuppositions of the mind that generated it. This does not mean that it is not really experienced. On the contrary, if consciousness survives the disintegration of the corpse, then mental images, projections, and memories are all that experience could possibly consist of, and these would seem very real indeed to experiencers.

In this ideational, nonmaterialistic realm, anything desired or imagined vividly would be experienced by the imaginer. The Pure Land Sutras explain that the person who longs for a banquet experiences seeing and tasting it, the person who wishes fancy clothing and palaces experiences being so clad and housed, and the person who wishes to bathe or swim finds bodies of water of the depth and temperature desired. This view of the Pure Land "utopia" has important implications both for moral development and for life in this world.

\section{Moral Rules Versus Search For Enlightenment}

The ideational aspect of experience means that in one sense, the Buddhist Pure Land is less "societal" than the utopian society; only those whom the deceased consciousness recognizes and admits can interact on the same ideational plane. Upon entering the Pure Land, we may find ourselves quite alone, except for whatever fellow beings we have the grace and openness to allow into our plane of vision. To the extent that our vision is self-centered, other beings never even enter our vision. We may for a time enjoy simply generating projected images of the riches and banquets and sports cars we might wish for; but precisely because all these wishes are spontaneously and instantaneously fulfilled, they soon become meaningless.

And if we become open to communing with other beings potentially in the same plane of consciousness, desires for rank, position, and material possessions pale. Since anyone can generate anything by mere thought, the point of conspicuous consumption is eliminated. Competition for superior material goods and appearances disappears. And thoughts incompatible with the well-being of fellow con- 
sciousnesses remove the appearances of those people from the level of consciousness on which we dwell, leaving us humbled and very much alone. The desire to see other people can only be consummated by communing with other minds, which presupposes a selfless receptivity and desire to understand the consciousness of others.

Thus even the least moral or spiritually motivated souls in the Pure Land would soon find that mere images lose their appeal. After enjoying the fruits of our subconscious desire-projections and subsequently interacting with other consciousnesses whom we admitted, we would soon be left with the question of what existence in the Pure Land realm of postmortem consciousness is all about. And we would come to the Buddhist answer: to overcome all vestiges of self-consciousness, to achieve true selflessness, or nirvana.

On earth, moral rules and social restrictions derive from the necessity of living in a world of limitations where our acts may injure or limit others. On earth, materiality and society are primary, and social or moral rules are the inescapable consequences of these conditions. In the Pure Land, however, consciousness exists in a realm "purified" of matter. All dealings with others presuppose a concern or altruistic love as a prerequisite to interaction. Without such a state of mind, others cannot even share our sphere of perception.

Morality is not the result of social rules, but the internal state of sensitivity to other minds that makes telepathic communication possible. Only after self-consciousness is subordinated, so we can recognize the essential being of others' consciousnesses, is social interaction achieved. Thus, in the Pure Land, morality is primary and essential, and social interaction a result. This morality is based on our own moral self-purification and understanding, not on rules or external codes.

\section{Deathlessness Versus Selflessness}

The transition from the Pure Land to nirvana could be considered the death of the person; for it is the disintegration of the last vestiges of discrete personal consciousness and the merging into an indescribable state of universal consciousness transcending individual selfhood. Some Western readers might abhor this ultimate death and elimination of personality. Indeed, as long as Pure Land dwellers desire to imagine and project an embodied existence, they are doomed to do so.

From the Buddhist perspective, it is fortunate that consciousness is not doomed to a quasi-material body for eternity, as Kellehear's NDErs report. Rather, transcendence of self is the ultimate "salvation" in 
Buddhism, and depends on the genuine dedication of consciousness to that goal. This death of personality and enlightenment into Ultimate Reality is a welcome alternative to eternal embodiment and spatiotemporality, but it will not be reached until the individual comes to that stage of realization.

\section{Implications For Earthly Life}

This vision of the Pure Land has important implications for our lives here and now. First, the ultimate agent of all activity is human consciousness, not money, fame, resources, nor the physical body with which we are presently equipped and burdened. The more we become entranced by sensualism and materialism, the more difficult will be our postmortem progress to a more enlightened state of consciousness. Conversely, if we live either a Buddhist or an Epicurean asceticism, we would be better prepared to control our desire-projections and closer to achieving selfless nirvana. We should strive to be more receptive and appreciative of others' feelings and consciousness than to outdo them.

Second, we are shown that consciousness is the author of experience. Consciousness may not influence the material world as much as it is said to influence the ideational world of the Pure Land; but it is obvious that our appreciation of beauty and sensitivity to pain are subject to the openness of our consciousness to those experiences.

The power of positive imaging in improving health and relationships is becoming increasingly recognized even by the heavily materialistic Western world. Buddhists would add that practice in meditation and image control, especially if done not for self-benefit but for selftranscendence, opens the way to clairvoyance, telepathy, precognition, and psychokinesis. These powers are not yet understood by Western paradigms that subordinate the roles of consciousness, but there is a growing research literature on these potentials.

Third, awareness that there is not only a death of the body but ultimately a transcendence of individuality is not only a solace but a spur to individual spiritual growth. Pure Land Buddhists hope to learn more of morality, but not through following the rules of a future society, nor through an automatic moral awakening upon death; they are inescapably and individually responsible for each step in the evolution from animal consciousness to a potentially transcendent human one over millions of years.

If Pure Land Buddhists use their minds badly on this level and fall back into rebirth as a human or animal rather than reaching the Pure 
Land at death, then they will be subject to all the physical ills and heartaches to which the flesh is heir. On the other hand, if they awaken to the truth that everything on earth is bound up with change, decay, and suffering, they will endeavor not only to transcend selfish perspectives, but to work compassionately for the alleviation of pain of present and future generations on earth. This includes killing as few living things as possible, respecting the important role of all beings in the balance of nature, and transcending personal desires. These ideals clearly provide the basis for a more humane and environmentally conscious world.

None of this addresses whether the Pure Land is "real" or imaginary; for like it or not, imagination may be all we have left after bodily death. My purpose, and Kellehear's, was to derive meaning from NDE visions and to imagine postmortem utopias. Some of the best minds of Asia over several millenia have devoted lifetimes to achieving, understanding, and interpreting such visionary experiences. Their visions of a postmortem Pure Land have greater credibility and coherence-and consistency with what we know about humankind and nature-than the utopias of J.C. Davis and Craig Lundahl's NDErs.

The Pure Land philosophy has important implications for selflessness and self-transcendence here and now. Pure Land Buddhists believe that their ideation-centered interpretation, coupled with a realization not only of the continuity of consciousness after physical death, but of the transience and relative unimportance of personal self in this death-doomed world, gives a consistent ontological and axiological perspective on which to work towards a more utopian life, whether here and now, or in some vision of a realm beyond death.

\section{References}

Becker, C.B. (1981). The centrality of near-death experiences in Chinese Pure Land Buddhism. Anabiosis: The Journal of Near-Death Studies, 1, 154-170.

Becker, C.B. (1984). The Pure Land revisited: Sino-Japanese meditations and near-death experiences of the next world. Anabiosis: The Journal of Near-Death Studies, 4, 51-68.

Hick, J.H. (1976). Death and eternal life. San Francisco, CA: Harper and Row.

Kellehear, A. (1990). The near-death experience as status passage. Social Science and Medicine, 31, 933-939.

Kellehear, A., Heaven, P., and Gao, J. (1990). Community attitudes toward near-death experiences: A Chinese study. Journal of Near-Death Studies, 8, 163-173. 